\title{
Klasterisasi Data Travel Umroh di Marketplace Umroh.com Menggunakan Metode K-Means
}

\author{
Mas'ud Hermansyah¹, Rifky Aditia Hamdan², Fazar Sidik², Arief Wibowo ${ }^{4}$ \\ Program Studi Magister IImu Komputer, Universitas Budi Luhur \\ JI.Raya Ciledug, Petukangan Utara, Jakarta Selatan 12260 Indonesia \\ ${ }^{1}$ masudhermansyah@gmail.com \\ 2rifkyaditia7@gmail.com \\ 3fajarsidik1430@gmail.com \\ 4arief.wibowo@budiluhur.ac.id
}

\begin{abstract}
Abstrak
Perjalanan wisata religi khususnya untuk ibadah umroh semakin diminati masyarakat. Umroh.com adalah jembatan antara calon jamaah umroh dengan travel umroh untuk bertransaksi didalam persiapan perjalanan ibadah umroh. Umroh.com sebuah perusajaan berbentuk marketplace dengan menawarkan produk paket umroh dan menyediakan travel umroh lebih dari 60 travel umroh terpercaya di Indonesia dengan izin resmi Kementrian Agama. Untuk dapat melakukan persaingan antar travel umroh, masing-masing travel membutuhkan strategi-strategi penjualan untuk dapat menarik minat calon jamaah umroh dan meningkatkan laba atau pendapatan perusahaan travel. Pada penelitian ini analisis data mining dilakukan dengan Teknik Clustering menggunakan metode K-Means. Hasil akhir dari penelitian ini adalah mengelompokkan data travel yang terdaftar di Umroh.com untuk mengetahui data travel yang memiliki potensi atau kecenderungan calon jamaah umroh dalam memilih travel umroh tersebut. Hasil penelitian menunjukkan bahwa pemodelan K-Means dengan jumlah klaster sebanyak 5 klaster memiliki nilai DBI terkecil yaitu sebesar 0,134.
\end{abstract}

Kata Kunci: Klasterisasi, Travel Umroh, Marketplace, K-Means, Davies Bouldin Index

Abstract

Religious tourism, especially for Umrah worship, is increasingly in demand by the public. Umroh.com is a bridge between prospective Umrah pilgrims and Umrah travel to make transactions in preparation for the Umrah pilgrimage trip. Umroh.com is a company in the form of a marketplace by offering Umrah package products and providing Umrah travel for more than 60 trusted Umrah travel agents in Indonesia with official permission from the Ministry of Religion. To be able to compete between Umrah travels, each travel needs sales strategies to attract prospective Umrah pilgrims and increase the profit or income of the travel company. In this study, data mining analysis was carried out by using the Clustering Technique using the K-Means method. The final result of this research is to classify the travel data listed on Umroh.com to find out which travel data has the potential or tendency of prospective Umrah pilgrims to choose the Umrah travel. The results showed that the K-Means modeling with the number of clusters of 5 clusters had the smallest $\mathrm{DBI}$ value of 0.134 .

Keywords: Clusterization, Umrah Travel, Marketplace, K-Means, Davies Bouldin Index

\section{Pendahuluan}

Teknologi data mining di dalam sebuah perusahaan digunakan untuk mempelajari bagaimana memanfaatkan data-data historis dengan menemukan suatu pola-pola yang pada dasarnya digunakan agar bisa membantu mempercepat dalam proses pengambilan keputusan secara tepat dan memungkinkan perusahaan untuk mengelola informasi menjadi sebuah pengetahuan yang baru. Melalui pengetahuan baru yang didapat, perusahaan diharapkan bisa meningkatkan pendapatannya, dan pada akhirnya dimasa yang akan datang perusahaan dapat lebih kompetitif [1]. 
Umroh.com adalah jembatan antara calon jamaah umroh dengan travel umroh untuk bertransaksi didalam perjalanan ibadah umroh. Umroh.com merupakan perusahaan swasta berbentuk marketplace dengan melayani penjualan produk paket umroh dan menyediakan paket umroh lebih dari 60 travel umroh terpercaya di Indonesia dengan izin resmi Kementerian Agama (Kemenag). Persiapan ibadah umroh akan terasa mudah karena calon jamaah umroh tidak lagi memusingkan untuk mencari travel umroh dan menemukan paket umroh yang diinginkan.

Meningkatnya jumlah data jamaah umroh pada penyedia layanan travel umroh tentunya memiliki variasi strategi yang berbeda-beda. Pengelompokan data travel umroh didalam marketplace Umroh.com merupakan salah satu tujuan untuk meningkatkan kualitas pelayanan dari masingmasing penyedia layanan travel umroh. Pengelompokan ini bertujuan untuk mengetahui minat calon jamaah umroh pada Umroh.com berdasarkan: jumlah jamaah yang sudah diberangkatkan pada masing-masing travel pada tahun 2019, rata-rata harga paket pada masing-masing travel, dan banyaknya paket umroh yang tersedia pada masing-masing travel umroh.

Pengelompokan tersebut dapat menggunakan metode pengelompokan algoritma K-Means Clustering. Clustering merupakan metode dalam data mining dan algoritma K-Means dipilih karena kesederhanaan algoritma dan efisiensinya. Hasil dari mengelompokkan data travel yang dipilih oleh jamaah umroh adalah untuk mengetahui data yang memiliki potensi atau kecenderungan pelanggan dalam memilih travel umroh tersebut. Hasil ini dapat digunakan untuk memberi saran pertimbangan dalam menentukan strategi pemasaran kepada masing-masing travel umroh.

\section{Metode Penelitian}

Metode yang digunakan dalam penelitian ini adalah metode data mining clustering dengan menggunakan algoritma K-Means.

\subsection{Data Mining}

Data mining merupakan salah satu bidang paling penting dalam penelitian yang bertujuan untuk memperoleh informasi dari data set. Data mining mulai ada sejak 1990-an sebagai cara yang efektif untuk mengambil pola dan informasi yang sebelumnya tidak diketahui dari suatu data set. Teknik data mining digunakan untuk menemukan hubungan antara data untuk melakukan pengklasifikasian yang digunakan dalam klasifikasi nilai-nilai dari beberapa variabel, membagi data yang diketahui menjadi kelompok-kelompok yang mempunyai kesamaan karakteristik (clustering). Data mining merupakan bagian dari proses penemuan pengetahuan dari basis data Knowledge Discovery in Databases (KDD), yang mana merupakan tahapan dari KDD [2].

\subsection{Klasterisasi}

Clustering merupakan sebuah teknik pemrosesan data yang digunakan untuk menemukan polapola tersembunyi pada kumpulan data [3]. Clustering atau klasterisasi adalah suatu alat bantu pada data mining yang bertujuan untuk mengelompokan objek-objek ke dalam beberapa klaster. Klaster adalah sekumpulan objek-objek data yang memiliki kemiripan karakteristik satu sama lain dalam klaster yang sama dan berbeda karakteristik terhadap objek-objek yang berbeda klaster [4].

Cara kerja teknik ini adalah dengan mengelompokkan sekumpulan data ke dalam kelas-kelas atau kluster-kluster, yang mana objek-objek yang ada pada kelas tersebut memiliki similaritas yang tinggi jika dibandingkan dengan objek lain yang ada dalam kelas tersebut, namun memiliki similaritas yang rendah jika dibandingkan dengan objek yang ada di kelas atau kluster lain [5].

\subsection{Algoritma K-Means}

Algoritma K-Means adalah metode yang termasuk dalam algoritma clustering berbasis jarak yang membagi data ke dalam sejumlah cluster dan algoritma ini hanya bekerja pada atribut numerik [6].

Metode dasar analisis algoritme K-Means Clustering adalah sebagai berikut:

a. Tentukan jumlah klaster (k), tetapkan pusat cluster secara acak.

b. Hitung jarak setiap data ke pusat cluster.

c. Kelompokan data ke dalam cluster dengan jarak yang paling pendek. 
d. Hitung pusat cluster baru.

e. Ulangi langkah 2 (dua) sampai 4 (empat) apabila masih ada data yang berpindah kelompok atau apabila ada perubahan nilai centroid di atas nilai ambang yang ditentukan.

Proses clustering dimulai dengan mengidentifikasi data yang diklasterisasi, dapat digunakan rumus formula Euclidean Distance seperti yang terlihat pada rumus persamaan (1) [5]. Untuk menghitung jarak semua data ke setiap tiitk pusat cluster dapat menggunakan teori jarak Euclidean yang dirumuskan sebagai berikut [7].

$$
d_{i j}=\sqrt{\sum_{k=1}^{m} X_{i j}-C_{j k}^{2}}
$$

Dimana $\mathrm{d}_{\mathrm{ij}}$ merupakan jarak objek antar nilai data dan nilai pusat cluster, $m$ adalah jumlah dimensi data, $\mathrm{X}_{\mathrm{ij}}$ merupakan nilai data dari dimensi ke-k dan $\mathrm{C}_{\mathrm{jk}}$ adalah nilai pusat cluster dari dimensi ke$\mathrm{k}[5]$.

Untuk menghitung centroid baru, dapat menggunakan rumus persamaan (2), sebagai berikut:

$$
C=\frac{\sum m}{n}
$$

Dimana $\mathrm{C}$ merupakan centroid data, $\mathrm{m}$ adalah anggota data yang termasuk ke dalam centroid tertentu dan $\mathrm{n}$ adalah jumlah data yang menjadi anggota centroid tertentu [5].

\subsection{Knowledge Discovery in Database (KDD)}

KDD adalah metode yang digunakan untuk dapat memperoleh pengetahuan yang berasal dari database yang ada. Hasil pengetahun yang diperoleh dapat dimanfaat kan untuk basis pengetahuan (knowledge base) yang digunkan dalam keperluan mengambil keputusan. Secara lebih detail, proses KDD seperti pada gambar berikut ini yang diadopsi dari [8]:

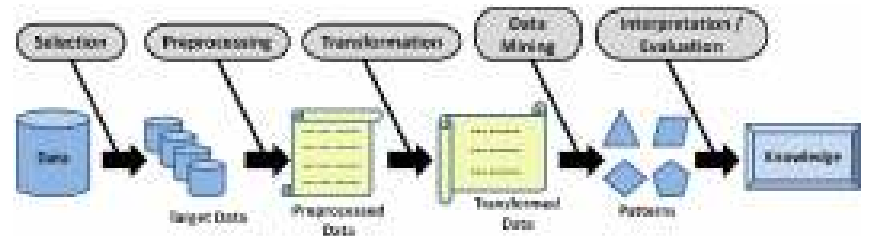

Gambar 1. Proses Knowledge Discovery in Database (KDD)

a. Data Selection

Bertujuan mentransformasikan data mentah ke dalam format yang sesuai untuk bisa dilakukan analisa. Terdiri atas proses seleksi fitur, normalisasi dan subsetting data [5].

b. Data Preprocessing

Pada prepocessing terdapat dua tahap, yaitu sebagi berikut:

1. Data Cleaning

Menghilangkan data yang tidak diperlukan seperti menangani missing value, noise data serta menangani data-data yang tidak konsisten dan relevan.

2. Data Integration

Dilakukan terhadap atribut yang mengidentifikasikan entitas yang unik [8].

c. Data Transformation

Transformasi pada data yang telah dipilih, sehingga data tersebut sesuai untuk proses data mining. Proses transformasi dalam KDD merupakan proses yang sangat tergantung pada jenis atau pola informasi yang akan dicari dalam basis data [9].

d. Proses Mining

Proses mining bertujuan untuk memberikan solusi kepada pengambil keputusan dalam bisnis guna meningkatkan kualitas bisnis perusahaan [10].

e. Interpretation / Evaluation 
Model informasi yang nantinya dihasilkan dari proses mining harus ditampilkan dalam bentuk yang mudah dimengerti oleh pihak yang bersangkutan. Pada tahap ini mencakup pemeriksaan apakah model atau informasi yang ditemukan dari proses data mining bertentangan dengan fakta atau hipotesis yang ada sebelumnya [11].

f. Knowledge

Pola-pola yang dihasilkan akan dipresentasikan kepada pengguna. Pada tahapan ini pengetahuan baru yang dihasilkan bisa dipahami semua orang yang akan dijadikan acuan pengambilan keputusan [8].

\subsection{Davies Bouldin Index}

Davies Bouldin Index (DBI) adalah menghitung rata-rata nilai setiap titik pada himpunan data. Perhitungan nilai setiap titik merupakan jumlah nilai compactness yang dibagi dengan jarak antara kedua titik pusat cluster sebagai separation [12].

Dalam proses penilaian dari model yang dihasilkan, digunakan Davies Bouldin Index. DBI digunakan untuk mengoptimalkan jarak diluar cluster dan meminimalkan jarak didalam cluster yang bisa dihitung dengan persamaan 3 berikut [5]:

$$
S_{i}=\frac{1}{|c i|} \sum_{x \in c i}\left\{\left|x-z_{i}\right|\right\}
$$

Dimana ci adalah banyaknya titik yang terdapat di dalam cluster $\mathrm{i}, \mathrm{x}$ adalah data, dan zi adalah centroid cluster i. Sedangkan jarak antar cluster didefinisikan pada Persamaan 4 berikut:

$$
d_{i j}=\left|Z_{i}-Z_{j}\right|
$$

Dimana zi adalah centroid dari cluster i dan zj adalah centroid dari cluster j. Perhitungan jarak dij dapat mengunakan euclidean distance. Selanjutnya mendefinisikan $R i$, untuk cluster ci pada persamaan 5 berikut:

$$
R_{i, q t}=\max _{j, j \neq 1}\left\{\frac{S_{i, i}+S_{j, q}}{d_{i j, t}}\right\}
$$

Selanjutnya Davies Bouldin Index didefinisikan pada persamaan 6 berikut:

$$
D B I=\frac{1}{k} \sum_{i=1}^{k} R i, q t
$$

Dari persamaan $6, \mathrm{k}$ merupakan jumlah cluster yang digunakan. Semakin kecil nilai yang diperoleh dari perhitungan DBI (non-negatif $>=0$ ), maka memberikan hasil semakin baik pula cluster yang diperoleh dari pengelompokan cluster dengan metode K-Means yang digunakan [13].

\section{Hasil dan Pembahasan}

Langkah-langkah untuk melakukan data mining mengikuti aturan KDD adalah sebagai berikut:

a. Data Selection

Data travel yang diolah merupakan data tahun 2019 dan memiliki atribut-atribut sebagai berikut:

1. Nama Travel

2. Alamat

3. Jamaah Keberangkatan

4. Harga Paket Umroh

5. Jumlah Paket Umroh

6. Tahun Izin Lisensi Umroh

7. Tahun Izin Lisensi Haji

8. Nomor Telepon

Dari atribut yang telah disebutkan sebelumnya, dipilih hanya empat atribut. yaitu:

1. Nama Travel

2. Jumlah Keberangkatan 
3. Harga Paket Umroh

4. Jumlah Paket Umroh

b. Data Preprocessing / Data Cleaning

Langkah ini dilakukan untuk membersihkan data duplikasi dan data yang tidak konsisten. Dalam penelitian ini proses cleaning adalah membersihkan nama-nama travel yang sama atau nama travel yang sudah tidak aktif.

c. Data Transformation

Transformasi dilakukan untuk menyesuaikan data agar dapat diproses. Transformasi yang dilakukan adalah atribut Harga Paket Umroh dan kemudian ditransformasi menjadi rata-rata total Harga Paket Umroh.

Tabel 1. Data Travel Umroh

\begin{tabular}{clcc}
\hline No & \multicolumn{1}{c}{ Nama Atribut } & $\begin{array}{c}\text { Tipe } \\
\text { Data }\end{array}$ & Nilai \\
\hline 1 & Nama Tarvel & Text & $\mathbf{A - Z}$ \\
2 & Jumlah Keberangkatan & Integer & $0-9$ \\
3 & Rata-rata Harga Paket & Integer & $0-9$ \\
4 & Jumlah Paket & Integer & $0-9$ \\
\hline
\end{tabular}

d. Proses Mining

Proses mining dilakukan dengan tujuan untuk mencari informasi atau pola untuk clustering dengan menggunakan algoritma K-Means. Implementasi algoritma K-Means dalam penelitian ini menggunakan software Rapidminer. Pemodelan K-Means Clustering dengan Rapidminer dapat dilihat pada Gambar 2.

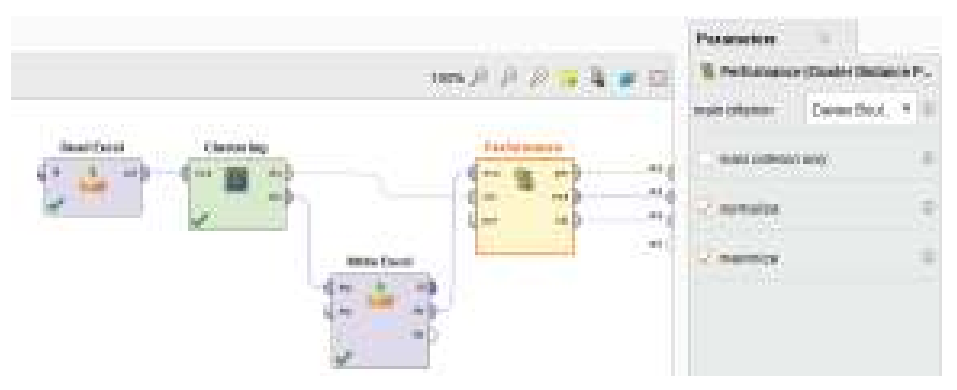

Gambar 2. Pemodelan K-Means Clustering dengan Rapidminer

- Read Excel adalah operator untuk membaca ExampleSet dari file Excel yang ditentukan.

- Clustering adalah operator yang melakukan proses pengelompokan menggunakan algoritma K-Means.

- Write Excel adalah operator untuk membuat laporan hasil clustering dengan tipe file .xlsx.

- Performance adalah operator yang digunakan untuk evaluasi kinerja metode clustering berdasarkan centroid.

Pada langkah ini dilakukan 5 kali percobaan proses pengklusteran dengan jumlah cluster mulai 2, 3, 4, 5, dan 6 cluster.

Tabel 2. Hasil Pemodelan K-Means Clustering dengan Rapidminer

\begin{tabular}{ccc}
\hline Jumlah Cluster & Nama Cluster & Jumlah Anggota \\
\hline \multirow{2}{*}{2 cluster } & Clsuter 1 & 61 \\
& Cluster 2 & 5 \\
\hline
\end{tabular}




\begin{tabular}{lcc}
\hline \multirow{3}{*}{3 cluster } & Clsuter 1 & 56 \\
& Cluster 2 & 1 \\
& Cluster 3 & 9 \\
\hline \multirow{3}{*}{ 4 cluster } & Cluster 1 & 26 \\
& Cluster 2 & 1 \\
& Clsuter 3 & 6 \\
& Cluster 4 & 33 \\
\hline \multirow{3}{*}{5 cluster } & Cluster 1 & 29 \\
& Clsuter 2 & 4 \\
& Cluster 3 & 11 \\
& Clsuter 4 & 1 \\
& Cluster 5 & 21 \\
\hline \multirow{3}{*}{6 cluster } & Cluster 1 & 21 \\
& Cluster 2 & 1 \\
& Cluster 3 & 4 \\
& Cluster 4 & 5 \\
& Cluster 5 & 18 \\
\hline
\end{tabular}

e. Interpretation / Evaluation

Langkah terakhir dari KDD ini dilakukan untuk menjelaskan makna dari setiap cluster yang terbentuk. Langkah ini dilakukan dengan cara membagi centroid dari iterasi terakhir dengan jumlah anggota setiap cluster-nya. Sehingga dapat disimpulkan deskripsi dari setiap cluster. Selain itu pada langkah ini juga melakukan evaluasi cluster dengan metode Davies Bouldin Index untuk menghitung rata-rata nilai setiap titik pada himpunan data [5].

Dilakukan beberapa kali percobaan terhadap model yang dibangun. Model pertama adalah melakukan clustering terhadap dataset tanpa melakukan normalize. Jumlah cluster ditentukan mulai dari 2, 3, 4, 5 dan 6. Hasil segmentasi yang terbentuk akan dievaluasi menggunakan Davies Bouldin Index. Davies Bouldin Index merupakan metode validasi cluster dari hasil clustering.

Tabel 3. Nilai Davies Bouldin Index Hasil Percobaan

\begin{tabular}{cc}
\hline Jumlah Cluster & Nilai DBI \\
\hline 2 cluster & 0,146 \\
3 cluster & 0,147 \\
4 cluster & 0,136 \\
5 cluster & 0,134 \\
6 cluster & 0,135 \\
\hline
\end{tabular}

Dari hasil percobaan yang dilakukan, algoritma K-Means dengan Rapidminer, jumlah 5 cluster menghasilkan kualitas cluster yang lebih baik dibandingkan dengan jumlah cluster 2, 3, 4, dan 6. Hasil evaluasi cluster menunjukkan bahwa algoritma K-Means dengan jumlah cluster 5 lebih optimal dengan nilai DBI paling kecil, sebesar 0.134 . Jumlah 5 cluster yang terbentuk dengan segmentasi sebagai berikut:

Tabel 4. Hasil Cluster

\begin{tabular}{ccl}
\hline Nama Cluster & Jumlah Anggota & \multicolumn{1}{c}{ Inisial Nama Travel } \\
\hline Cluster 1 & 29 & AATOWA, AATR, \\
& ABDAAN, ADDBHUA, \\
& ALITVEL, ABAZHA, \\
& BMI, BTVL, BMW, \\
& DDTL, DNSTL, GABI, \\
& GMAWA, HASWD, \\
& KAJ, KIT, KOAPRNG, \\
& MDITRVL, MWSTA, \\
& MNRWSTA, MFRTUR, \\
\hline
\end{tabular}




\begin{tabular}{cc}
\hline & NAN, PTITHU, \\
& QBTWST, RHMTUR, \\
& SUMRAH, TIBITUR, \\
& TRZTRVEL, WINTUR \\
\hline Cluster 2 & ANSATRVL, CTL, \\
& PATRVL, STUR \\
\hline Cluster 3 & AHZ, AG, ADSTUR, \\
& AGGTP, FHY, GLSA, \\
& KZZHTUR, MTMUTM, \\
& PAZZWA, TNMTHH, \\
& TDTIO \\
\hline Cluster 4 & AANUL \\
\hline & AHZ, AFATRS, \\
& AFHMAISI, AMRA, \\
& BCMI, BTITUR, CAW, \\
& FTHIH, GTTS, JJKIMI, \\
& JDHTR, MTTVEL, \\
& MBATUR, PNATUR, \\
& RBITUR, RSITUR, \\
& RTTRVL, STUR, \\
& SOLUTUR, TCUTMA, \\
& ZITTUR \\
\hline
\end{tabular}

Dari data tabel di atas yang terlihat bahwa cluster 1 merupakan kelompok travel umroh dengan jumlah keberangkatan besar dengan nilai keberangkatan mencapai 8.000 jamaah, rata-rata harga paket tergolong murah, antara Rp. 17.000.000,00 - Rp. 25.000.000,00, rata-rata pilihan paket umroh cukup banyak, yaitu mencapai 30 paket umroh yang tersedia, dan tahun pendirian travel antara tahun 1988 sampai tahun 2017.

Cluster 2 merupakan kelompok travel umroh dengan jumlah keberangkatan rendah, yaitu dibawah 3.200 jamaah, dengan harga paket tergolong mahal yaitu dengan biaya sekitar Rp. 40.000.000,00, rata-rata pilihan paket umroh relatif banyak, yaitu 70 paket umroh yang tersedia, dan tahun pendirian travel antara tahun 1972 sampai tahun 2009.

Cluster 3 merupakan kelompok travel umroh dengan jumlah keberangkatan cukup rendah yaitu di bawah 2.500 jamaah, rata-rata harga paket tergolong mahal yaitu ratarata sebesar Rp. 30.000.000,00 rata-rata pilihan paket umroh relatif banyak, yaitu 70 paket umroh yang tersedia, dan tahun pendirian travel antara tahun 1989 sampai tahun 2017.

Cluster 4 merupakan kelompok travel umroh dengan jumlah keberangkatan sangat rendah dengan jumlah keberangkatan dibawah 280 jamaah, rata-rata harga paket tergolong sangat mahal, yaitu mencapai Rp. 60.000.000,00, rata-rata pilihan paket umroh sangat sedikit, yaitu hanya 4 paket umtoh yang tersedia, dan tahun pendirian travel tahun 1999.

Cluster 5 merupakan kelompok travel umroh dengan jumlah keberangkatan relatif tinggi dengan jumlah keberangkatan mencapai 6.000 jamaah, rata-rata harga paket tergolong relatif murah, yaitu antara $\mathrm{Rp}$. 25.000.000,00, sampai $\mathrm{Rp}$. 30.000.000,00, rata-rata pilihan paket umroh sanga banyak, yaitu 120 paket umroh yang tersedia, dan tahun pendirian travel antara tahun 1971 sampai tahun 2018.

\section{Kesimpulan}

Penerapan metode K-Means dalam pengelompokan data travel umroh pada marketplace Umroh.com dapat menghasilkan kelompok daftar travel yang paling diminati, cukup diminati dan kurang diminati. Hasil klasterisasi dapat menjadi rujukan bagi manajemen untuk mengatur strategi pemasaran kepada masing-masing travel umroh. Berdasarkan hasil pengelompokkan diperoleh pengelompokan dengan 5 cluster merupakaan hasil pengelompokan yang paling optimal dengan nilai DBI terkecil, yaitu 0,134 . Kondisi ini merupakan representasi dari hasil pengolahan data pelanggan atau jamaah yang mendaftar pada web http://www.umroh.com. 


\section{Referensi}

[1] A. Sani, "Penerapan Metode K-Means Clustering Pada Perusahaan Penerapan Metode K- Means Clustering Pada Perusahaan," ResearchGate, no. August, p. 7, 2018.

[2] Z. Mustofa and I. S. Suasana, "Algoritma Clustering K-Medoids Pada E-Government Bidang Information And Communication," J. Teknol. dan Komun., vol. 9, pp. 1-10, 2018.

[3] I. A. Musdar and A. SN, "Metode RCE-Kmeans untuk Clustering Data," IJCCS, vol. 9, no. 2, pp. 157-166, 2015.

[4] N. R. W, S. Defiyanti, and M. Jajuli, "Implementasi Algoritma K-Means dalam Pengklasifikasian Mahasiswa Pelamar Beasiswa," J. IIm. Teknol. Inf. Terap., vol. I, no. 2, pp. 62-68, 2015.

[5] I. R. Mahartika and A. Wibowo, "Data Mining Klasterisasi dengan Algoritme K-Means untuk Pengelompokkan Provinsi Berdasarkan Konsumsi Bahan Bakar Minyak Nasional," in Prosiding Seminar Nasional Sisfotek, 2019.

[6] W. M. P. Dhuhita, "Clustering Menggunakan Metode K-Means Untuk Menentukan Status Gizi Balita,” J. Inform., vol. 15, no. 2, pp. 160-174, 2015.

[7] R. Sibarani and Chafid, "Algorithma K-Means Clustering Strategi Pemasaran Penerimaan Mahasisswa Baru Universitas Satya Negara Indondesia [Algorithma K-Means Clustering Strategy Marketing Admission Universitas Satya Negara Indonesia]," Semin. Nas. Cendekiawan, vol. 4, pp. 685-690, 2018.

[8] M. H. Adiya and Y. Desnelita, "Penerapan Algoritma K-Means Untuk Clustering Data Obat-Obatan Pada RSUD Pekanbaru," J. Nas. Teknol. dan Sist. Inf., vol. 01, pp. 17-24, 2019.

[9] Y. Asriningtias and R. Mardhiyah, "Aplikasi Data Mining untuk Menampilkan Informasi Tingkat Kelulusan Mahasiswa," J. Inform., vol. 8, no. 1, pp. 837-848, 2014.

[10] M. H. Siregar, "Klasterisasi Penjualan Alat-Alat Bangunan Menggunakanmetode K-Means (Studi Kasus Di Toko Adi Bangunan)," J. Teknol. dan Open Source, vol. 1, no. 2, pp. 8391, 2018.

[11] D. Mukhibah and A. Kurniawati, "Implementasi Data Mining dalam Prediksi Performance Software Engineeri PT. Emerio Menggunakan Decision Tree," J. Inform. dan Komput., vol. 22, no. 1, pp. 31-43, 2017.

[12] A. F. Khairati, A. A. Adlina, G. F. Hertono, and B. D. Handari, "Kajian Indeks Validitas pada Algoritma K-Means Enhanced dan K-Means MMCA," in Prosiding Seminar Nasional Matematika, 2019, vol. 2, pp. 161-170.

[13] F. Ramdhan, A. Hoyyi, and Moch Abdul Mukid, "Pengelmpokan Provinsi di Indonesia Berdasarkan Karakteristik Kesejahteraan Rakyat Menggunakan Metode K-Means Cluster," J. Gaussian, vol. 4, no. 2006, pp. 875-884, 2015. 